
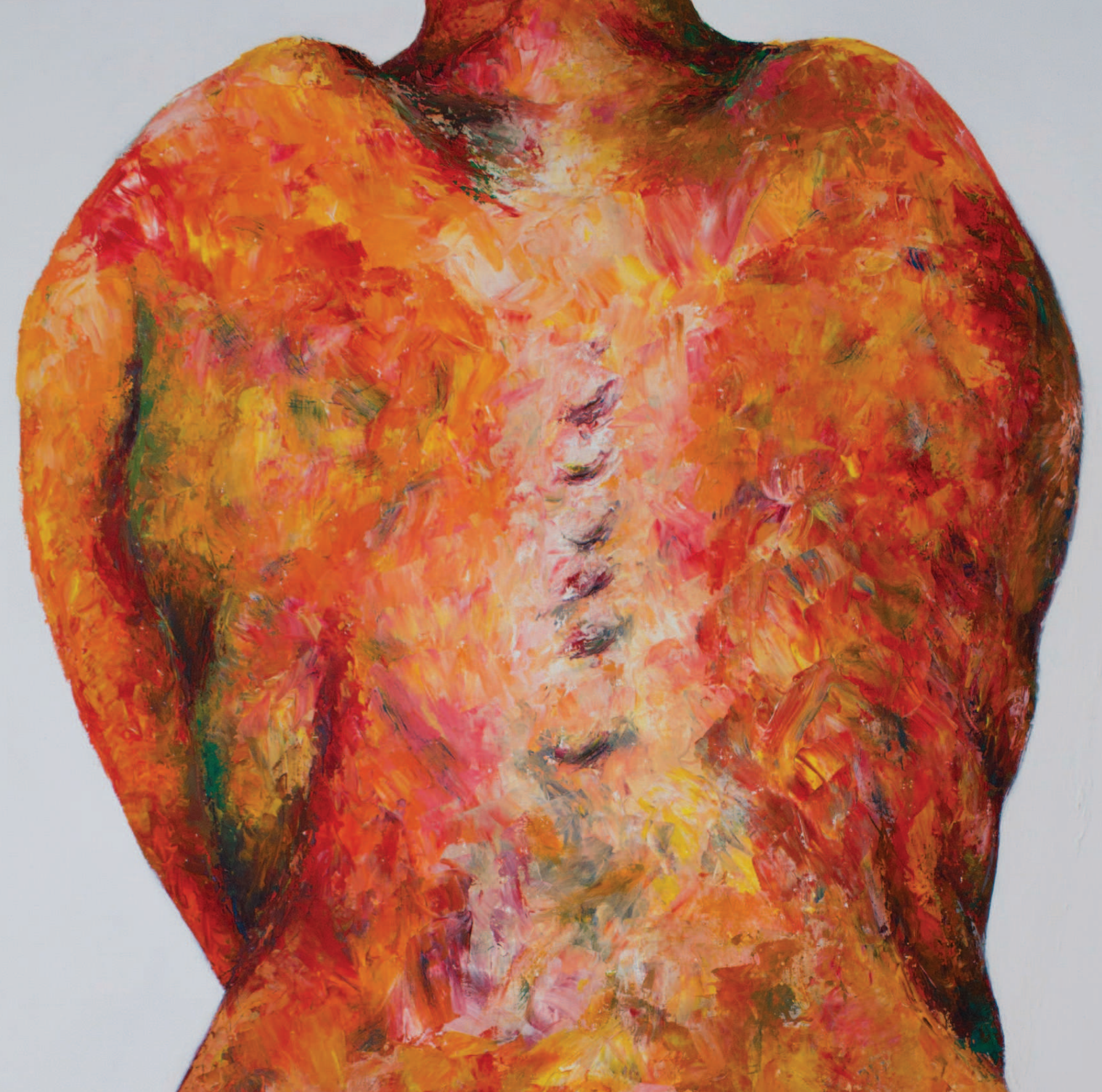

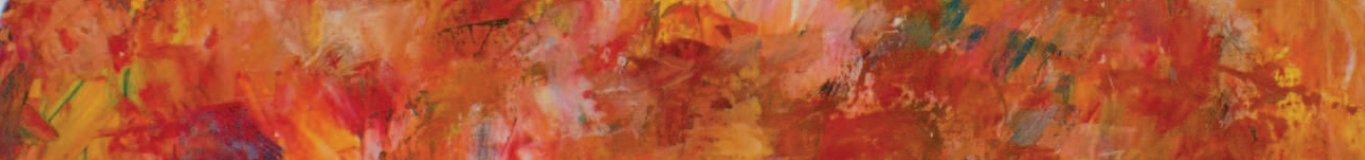

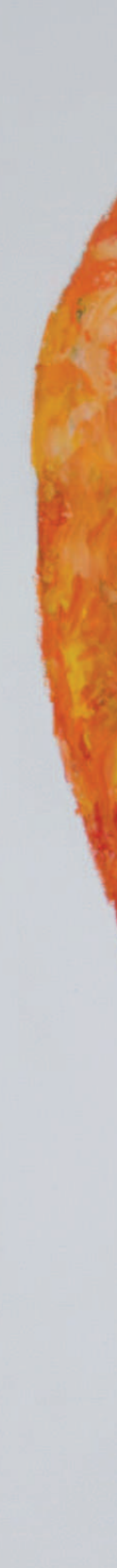

1

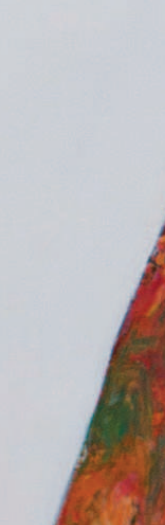

2.

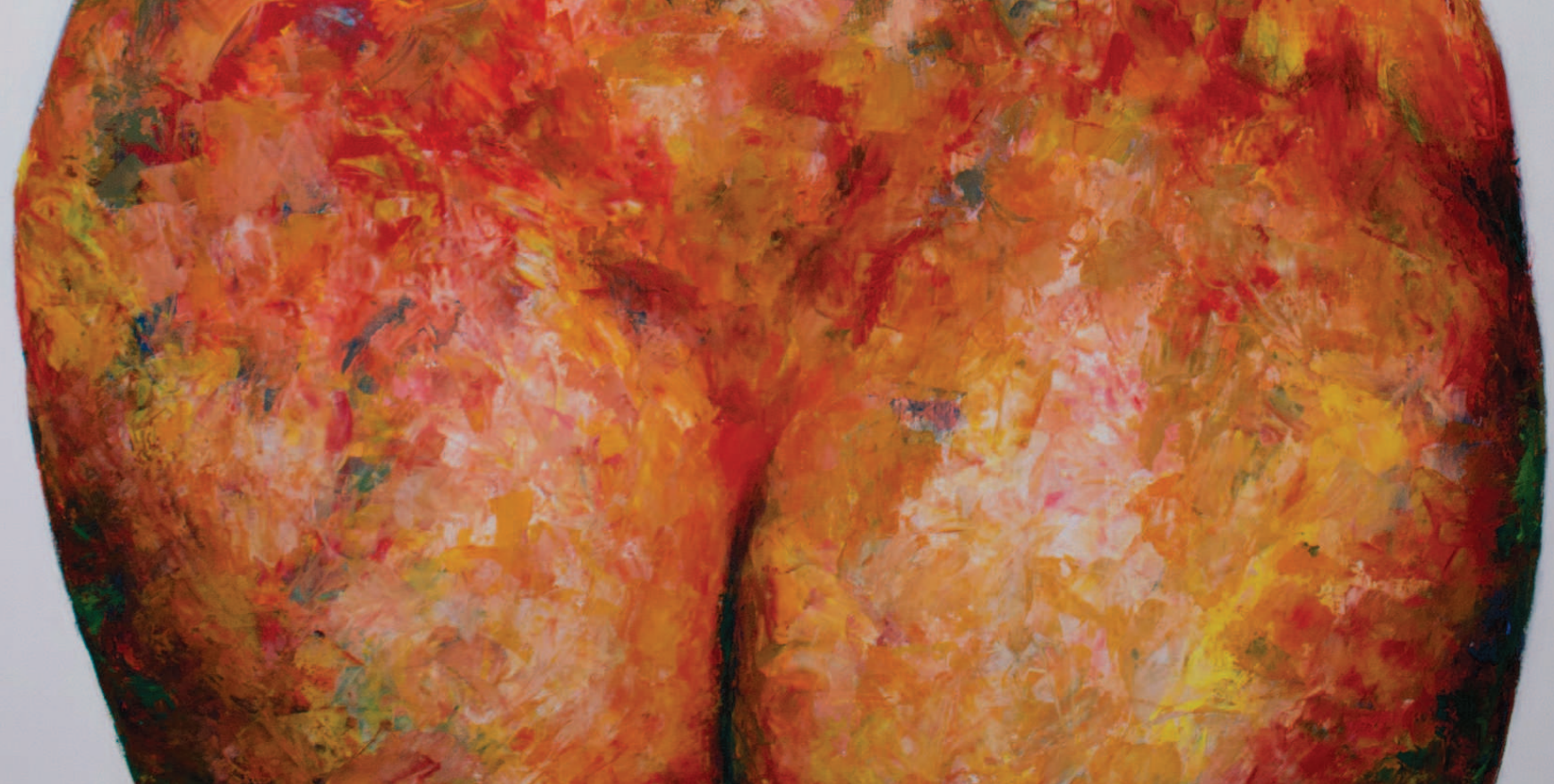




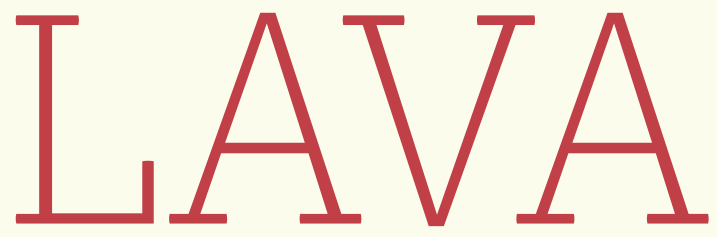

Matéria liquida lançada pelos vulcões.

Torrente, enxurrada, curso. 


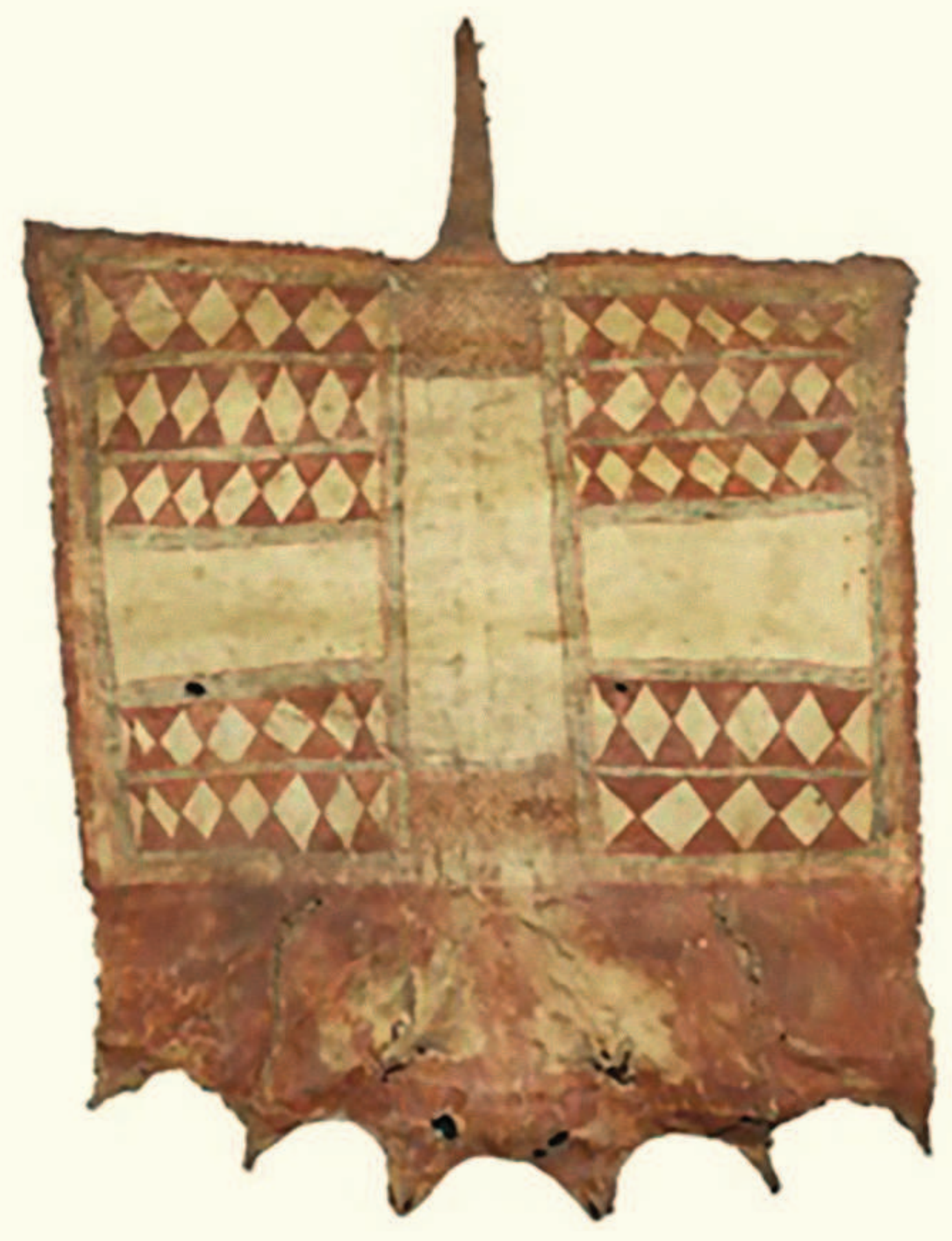

\section{LITERATURAS DA FLORESTA}

Textos de conclusão do curso ministrado no segundo semestre de 2014 e indicados para publicação pela Profa Lúcia Sá. 


\title{
REFLEXÕES SOBRE O INDIANISMO EM GONÇALVES DIAS
}

\author{
- ANA CAROLINA SÁ TELES
}

\section{RESUMO}

Este artigo aborda a poesia indianista de Gonçalves Dias, observando como o poeta se apropriou de fontes indiretas sobre as sociedades ameríndias. Essas fontes são constituídas pelo conjunto de escritos do período colonial. Objetiva-se problematizar o lugar-comum de que a caraterização do indígena na obra de Gonçalves Dias seja uma mera reprodução de modelos do medievalismo cristão. Assim, recorre-se à recepção de Gonçalves Dias por meio da crítica de Antonio Candido, Alfredo Bosi, Cláudia Neiva de Matos, Lúcia Sá e David Treece. Também foram lidos cronistas e viajantes como Hans Staden, Pero de Magalhães Gândavo, Jean de Léry e Claude d'Abbeville.

Palavras-chave: Gonçalves Dias, Indianismo, caracterização, recepção crítica, escritos coloniais.

\section{ABSTRACT}

This essay approaches Idianist poetry by Gonçalves Dias observing how he read and incorporated indirect sources about Amerindians. These sources were mainly constituted by the collection of colonial texts. The essay aims to question the commonplace critical idea that Golçavian "Indians" are the mere reproduction of chivalric and Christian models. With that idea in mind, I refer to the critical reception of Dias' works developed by Antonio Candido, Alfredo Bosi, Cláudia Neiva de Matos, Lúcia Sá, and David Treece. Also, chronicles and explorers' texts are part of the references in the essay.They include Hans Staden, Pero de Magalhães Gândavo, Jean de Léry, and Claude d'Abbeville.

Keywords: Gonçalves Dias, Indianism, characterization, critical reception, colonial texts.

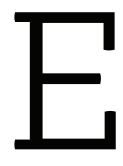
ste artigo pretende refletir sobre alguns aspectos do indianismo em Gonçalves Dias. Em sua obra, poemas que contemplam o tema são, por exemplo: "O canto do guerreiro", "O canto do piaga”, "O canto do índio" e "Deprecação", nas Poesias americanas 
dos Primeiros cantos (1846); "Tabira", de Segundos cantos (1848); e "O gigante de pedra", "Leito de folhas verdes", "I-Juca-Pirama”, "Marabá", "Canção do Tamoio", "A mãe-d'água”, nas Poesias americanas dos Últimos cantos (1850). Há também Os Timbiras (Poema Americano), obra incompleta cujos cantos iniciais foram publicados em 1857. Observa-se que esses poemas de Gonçalves Dias estruturam-se pelo Indianismo. No entanto, não se pode deixar de notar que outros poemas seus também dialogam em menor grau com elementos de nacionalidade e de culturas indígenas.

Um dos problemas que abordarei decorre do questionamento de críticos como Lúcia Sá e David Treece a respeito da recepção do Indianismo romântico. $\mathrm{O}$ que eles ponderam é que a crítica muitas vezes comentou o movimento como um só bloco. Nesse sentido, Sá e Treece defendem que a leitura das obras indianistas possa ser produtiva, se conduzida em termos dos diferentes autores:

\footnotetext{
Desde a época da primeira publicação de suas obras, os indianistas têm sido incessantemente acusados de haverem virado as costas para a questão da escravidão negra. Essas acusações são justas e necessárias em relação à maioria dos escritores, mas, em nome delas, o indianismo tem sido indiscriminadamente relegado à categoria de literatura pouco séria ou de simples imitação de modelos europeus sem qualquer conexão com as culturas indígenas do Brasil. Esses rótulos genéricos pouco ajudam a compreender diferenças importantes entre os autores e a complexidade de movimento que, apesar de todas as falhas, tentou encarar problemas complicados, como o contato entre culturas, a identidade nacional, a legitimidade do discurso histórico e a necessidade de se abrir a cultura brasileira para uma nova sensibilidade estética (SÁ, 2012, p. 201).
}

Portanto, em Literaturas da floresta, Lúcia Sá investiga a relação intertextual que Gonçalves Dias estabeleceu com fontes de temática indígena, de forma indireta, por meio dos cronistas coloniais. Sá interpreta que os poemas de Gonçalves Dias conferem atenção especial não só à formação social tupi, mas também às canções ameríndias.

Ou seja, os poemas de Gonçalves Dias estruturam-se por meio de recursos formais que remetem à função de canções indígenas. Além disso, a caracterização poética que sua obra desenvolve de índios e de sua cultura estabelece um elo criterioso com a tradição de textos do período colonial. Ademais, sua obra poética demonstra preocupação em descrever cronologicamente o processo de colonização, denun- 
ciando o genocídio perpetuado pelos colonizadores brancos contra os índios (sÁ, p. 189).

Na visão da autora, essas características do Indianismo de Gonçalves Dias diferenciam-no, por exemplo, do Indianismo praticado por José de Alencar nos romances O Guarani (1857), Iracema (1865) e Ubirajara (1874). Dessa forma, segundo Sá, no projeto estético do romancista, os personagens indígenas são caracterizados como europeus não corrompidos pela civilização (sÁ, p. 188).

Assim, os índios alencarianos formam-se como eco do bom selvagem, de Rousseau. A questão, inclusive, faz parte de um problema mais amplo em Alencar, relativo à composição de personagens originários de culturas que sofrem opressão no contexto do século 19. Contudo, os índios de Alencar não poderiam deixar de ser influentes na recepção crítica, dada a grande repercussão do autor nas letras brasileiras. Nesse sentido, Lúcia Sá aponta um problema da crítica:

O “cavaleiro indígena” de Alencar tornou-se sinônimo, na crítica literá-
ria, do próprio indianismo. As diferenças entre Alencar e seus contem-
porâneos são, em geral, ignoradas por críticos ansiosos em perpetuar
o que talvez seja um dos clichês mais difundidos na historiografia
literária brasileira: todos os índios criados pelos indianistas são simples
versões coloridas e exóticas de heróis medievais europeus (sÁ, p. 188).

David Treece também analisa, de forma diferente, o Indianismo de Gonçalves Dias, ao aproximá-lo dos relatos dos cronistas. Assim, ele aborda a poesia indianista de Dias como voltada em grande parte para o ponto de vista das culturas ameríndias, mesmo que essa referência tenha sido feita por fontes indiretas.

Segundo Treece, existe uma complexa relação ideológica de Gonçalves Dias com a política do Império, por um lado, e com os grupos nas bordas da sociedade do século 19, por outro. Como observa o crítico, a relação ideológica do poeta com esses dois polos imprime grande intensidade à sua obra:

Como tendência dissidente, embora menor, no interior do movimento romântico do Brasil, suas obras, dentro do limitado espaço político disponível, fizeram uso do cenário indianista para traçarem comparações implícitas, porém perturbadoras, entre as formas de opressão sofridas pelas raças subjugadas do Brasil sob domínio colonial e a persistente negação das liberdades sociais e políticas à maioria, após a Independência (TREECE, 2008, p. 139). 
No entanto, apesar de representar, como Teixeira e Sousa, uma tendência dissidente bastante atípica dentro do quadro estrutural predominantemente conservador do movimento, Gonçalves Dias nunca foi tão longe a ponto de questionar os pressupostos integracionistas básicos do pensamento indianista. Sua obra e carreira demonstram a mesma acomodação dos princípios liberais radicais aos interesses de um estado centralizado, oligárquico e escravocrata que caracteriza o movimento como um todo. O que torna o indianismo de Gonçalves Dias tão interessante é que este compromisso ideológico existe em estado de tensão que dá à sua obra uma intensidade que não se encontrará em nenhum outro colega de sua geração (TREECE, p. 149).

Antonio Candido é um dos críticos exponenciais da recepção tradicional de Gonçalves Dias, mas não deixa de reconhecer a diferença entre o poeta e seus contemporâneos. No início do capítulo da Formação da literatura brasileira (1959) que se intitula justamente "Gonçalves Dias consolida o Romantismo", ele afirma: "Gonçalves Dias se destaca no medíocre panorama da primeira fase romântica pelas qualidades superiores da inspiração e consciência artística" (CANDIDO, 2007, p. 401).

Candido comenta que Gonçalves Dias foi o poeta decisivo do Romantismo. Somente a partir dele, os poetas posteriores teriam desenvolvido o movimento. Candido menciona, aliás, como os escritores que sucederam Dias comentaram principalmente a "poesia nacional" e o Indianismo daquele, embora o crítico defenda a percepção de que mais conteúdos e recursos poéticos tenham ressoado com grande impacto nos sucessores:

Embora os sucessores hajam destacado a "poesia nacional", o Indianismo, nele encontraram muito mais: o modo de ver a natureza em profundidade, criando-a como significado, ao mesmo tempo em que a registravam como realidade; o sentido heroico da vida, superação permanente da frustração; a tristeza digna, refinada pela arte; no terreno formal, a adequação dos metros à psicologia, a multiplicidade dos ritmos, a invenção da harmonia, segundo as necessidades expressionais, o afinamento do verso branco. Mesmo quando se abandonaram à incontinência afetiva e à melopéia; mesmo quando buscaram modelos em poetas estrangeiros - sempre restava neles algo de Gonçalves Dias, cuja obra, rica e variada, continha inclusive o germe de certos desequilíbrios que as gerações seguintes cultivarão (CANDIDo, p. 403).

Candido pertence à linha crítica que interpreta o indianismo de Gonçalves Dias como continuação do "medievismo coimbrão" (CANDIDO, 
p. 403). Assim, ele aproxima poemas de As sextilhas de frei Antão, que seguem o modelo medieval, a poemas centrais da poesia americana. Segundo o crítico, o índio em Gonçalves Dias é reduzido ao padrão heróico da cavalaria:

\footnotetext{
Note-se que o Indianismo de Gonçalves Dias, mais que o das balatas de Norberto, é parente do medievismo coimbrão, que praticou in loco e deve ter influído no seu propósito de aplicar à pátria o mesmo critério de pesquisa lírica e heroica do passado. As sextilhas de Frei Antão, O soldAdo ESPANHOL, O TROVADOR (poemas medievistas) poderiam ser considerados pares simétricos d'Os timbiras, do I-Juca Pirama, da CANÇÃo do Guerreiro, pela redução do índio aos padrões da cavalaria (CANDIDO, p. 403).
}

Lembremos que David Treece concorda com a semelhança entre indianismo e medievalismo. Porém, ele questiona essa passagem de Antonio Candido, ao observar como poemas de As sextilhas de Frei Antão são abertamente racistas quanto à figuração do mulçumano, além de aderirem ao ponto de vista da reconquista cristã (TREECE, p. 181). Para Treece, o espírito marcial das Sextilhas de Frei Antão enquadra-se num projeto cultural e político de reconquista, enquanto o espírito marcial das poesias americanas, diferentemente, faz parte do ethos da sociedade tribal (TREECE, p. 181).

Ainda assim, creio que existam contradições no texto de Antonio Candido. Na passagem supracitada, ele afirma que Gonçalves Dias praticou o "medievismo coimbrão in loco" (CANDIDo, p. 403). Contudo, em momento posterior, defende que Gonçalves Dias não poderia ser identificado como "poeta português" e que teria antes apreendido a "sensibilidade e o gosto brasileiros" (CANDIDO, p. 408).

Candido considera infundado o argumento de que o escritor indianista devesse compreender melhor a cultura indígena para melhor praticar o movimento, já que este seria formulado por um grupo europeizado (CANDIDO, p. 405). No entanto, ele considera o índio de Gonçalves Dias mais simbólico, enquanto o índio de Alencar parece-lhe mais particularizado, no sentido de estar mais próximo do leitor do público romântico (CANDIDO, p. 404). Ademais, ele defende que o índio de Gonçalves Dias é mais autêntico que o de Magalhães, o de Porto-Alegre e o de Norberto (CANDIDO, p. 405). De qualquer forma, justifica que o índio gonçalvino é "mais índio", mas, antes de tudo, "mais poético" (CANDIDO, p. 405).

Assim, percebe-se que Candido diferencia Gonçalves Dias no quadro do movimento indianista, destacando-o. Contudo, o crítico estabelece essa diferença antes por meio de aspectos estéticos que expressam a 
criação de uma "convenção poética nova" (CANDIDo, p. 404) do que propriamente por meio da forma de tratamento da temática indígena: "Esse cocktail de medievismo, idealismo e etnografia fantasiada nos aparece como construção lírica e heroica, de que resulta uma composição nova para sentirmos os velhos temas da poesia ocidental" (CANDIDO, p. 404). No entanto, permanece para nós a pergunta sobre por que o crítico afirma que o índio gonçalvino é "mais índio" (CANDIDo, p. 405), ainda que essa característica tenha sido relevada para segundo plano.

Alfredo Bosi na História concisa da literatura brasileira (1970) também desenvolve a relação entre Indianismo e medievalismo (BOSI, 1975, p. 110). O crítico aproxima Varnhagen, Alencar e Gonçalves Dias como participantes de um mesmo complexo ideológico: "O índio, fonte da nobreza nacional, seria, em princípio, o análogo do 'bárbaro', que se impusera no Medievo e construíra o mundo feudal: eis a tese que vincula o passadista da América ao da Europa" (BosI, p. 110).

No entanto, assim como Candido, ele reconhece o grau de originalidade da obra de Gonçalves Dias em relação aos outros escritores do movimento no Brasil. Ademais, reconhece que o tema indígena em Gonçalves Dias é de fato "matéria de poesia", enquanto, para os sucessores, teria sido apenas "moda" (BOSI, p. 115). De qualquer forma, Bosi observa, junto ao julgamento crítico de Herculano sobre Gonçalves Dias, que o poeta brasileiro compôs uma poesia americana com uma tendência portuguesa "no trato da língua e nas cadências garrettianas do lirismo" (воsi, p. 115).

Por um lado, ele aproxima a poesia de Gonçalves Dias da de demais românticos pela via do conservadorismo, mas, por outro, destaca-a em função da temática bélica indígena e da linguagem peculiar:

\footnotetext{
Mas é apenas o matiz conformista que pode aproximar os versos do maranhense aos de Magalhães, Porto Alegre e Varnhagen. O que nestes era prosaico e flácido aparece, na arte de G. Dias, transposto em ritmos ágeis e vazado numa linguagem precisa em que logo se conhece o selo de um espírito superior. Desde as "Poesias Americanas", expressão dos valores bélicos (fulcro do Indianismo épico), o artista entra no tom justo dos versos breves, fortemente cadenciados e sabiamente construídos nas sua alternância de sons duros e vibrantes (BosI, p. 116).
}

Já em 1988, Cláudia Neiva de Matos conduziu um estudo voltado exclusivamente à obra indianista do poeta: Gentis Guerreiros: o Indianismo de Gonçalves Dias. Matos dá continuidade à leitura de Antonio Candido na Formação da Literatura Brasileira, compreendendo o nacionalismo e o 
[1] Quanto ao problema da construção da utopia indígena e sua destruição, em Gonçalves Dias, conferir crítica de Lucia Sá. Sá problematiza a questão em grande escala, já que esta se encontra intrincada com a violência: "No entanto, para as nações tupis do litoral brasileiro, a destruição representada pela chegada dos brancos foi um fato inquestionável. Milhões de seres humanos morreram nos primeiros anos de colonização, inúmeros outros foram escravizados, mulheres e crianças foram raptadas, sua terra foi irrecuperavelmente roubada, sua religião e seus sistemas de crenças foram ferozmente atacados. Chamar esse processo de 'queda do paraíso' seria equivalente a descrever o Holocausto como 'queda judaica do paraíso': nenhuma ideia de paraíso é necessária para se compreenderem certos níveis de violência e destruição. Se as sociedades indígenas eram ou não paradisíacas ou utópicas (uma afirmação que Gonçalves Dias nunca faz), isso pouco altera a violência que de fato sofreram" (SÁ, p. 199-200). indianismo de Gonçalves Dias como práticas europeizadas que resultam, contudo, num "senso de americanidade" (MATOS, 1988, p. 15).

A esse respeito, Matos cita o trecho de Antonio Candido que discorre sobre como Gonçalves Dias se baseou no medievismo coimbrão, mas "criou uma convenção poética nova" (CANDIDo Apud MATOS, pp. 1516). A crítica argumenta que o paradoxo dessa ideia é apenas aparente. Ou seja, o excerto de Antonio Candido que comentei acima como uma forma de contradição, Cláudia Neiva de Matos menciona enquanto argumento sintético do crítico.

No entanto, creio que também no livro de Cláudia Neivas de Matos ocorra contradição entre: por vezes reconhecer o diálogo específico de Gonçalves Dias com culturas indígenas; e por vezes fazer prevalecer na interpretação da poesia gonçalvina o recurso à tradição europeia do medievalismo. No fim, Matos prefere à chave de leitura ocidentalizada.

Matos cita, por exemplo, os seguintes elementos na poesia de Gonçalves Dias: uma ética cortês que preside a guerra indígena (pp. 27- 28); a mítica do cavaleiro feudal aliada à mítica do bom selvagem na caracterização dos índios (p. 28); a construção de uma utopia indígena, ao lado da destruição da mesma (p. 39) ${ }^{1}$; o ideal cavaleiresco projetado sobre "um grupo étnico" "semidesconhecido" (p. 65); e uma reflexão final sobre como a obra de Gonçalves Dias alinha-se à defesa de um princípio monárquico ou, em suma, a uma ideologia reacionária (p. 82).

No entanto, Matos reconhece que a ética cortês é acompanhada de "exortações pedagógicas" dirigidas pelos índios mais velhos enquanto aspecto social que também preside a guerra (MATOS, p. 28). A crítica reconhece, aliás, que enquanto o bom selvagem e o promeneur, de Rousseau, realizam-se de maneira solitária (ou seja, em oposição à sociedade), a caracterização do índio em Gonçalves Dias, diferentemente, desenvolve-se com a presença imprescindível da estrutura social com "a lei guerreira" (mATos, p. 51). Ademais, a autora admite o uso do "acento indígena" em Marabá (MATOS, pp. 71-74).

No fim, contudo, a leitura de Cláudia Neiva de Matos tende à intepretação de referencial medievalista. Nesse sentido, se insistirmos no significado que, para a poesia de Gonçalves Dias, tiveram os cronistas e as fontes nas quais se descrevem os indígenas, encontraremos uma defesa curiosa da crítica. Segundo Matos, o conceito de guerra desenvolvido por Gonçalves Dias nas Poesias americanas seria fundado em Montaigne:

Assim é que na poesia de Gonçalves Dias, acerca da guerra entre os selvagens, prevalecerá a visão de Montaigne, e não as pesquisas dos viajantes. Mesmo em O Brasil e a Oceania, há passagens que sublinham, 
como explicação para os conflitos tribais, antes a afirmação de um valor moral avalizado simultaneamente pela índole e pela instituição, que o simples antagonismo vingativo (MATOS, pp. 25-26).

É interessante que Cláudia Neiva de Matos associe o indianismo gonçalvino à referência do ensaio de Montaigne, "Dos canibais" (1580). Isto porque o filósofo francês desenvolveu uma reflexão sobre o canibalismo que é a mais próxima, naquele período, do campo que se constituiria como antropologia moderna.

Nesse sentido, é interessante igualmente lembrar a interpretação de "I-Juca-Pirama" formulada por David Treece. Para o crítico, Gonçalves Dias foi o único autor do século 19, no Brasil, que se apropriou positivamente do canibalismo, figurando-o enquanto prática filosófica das sociedades ameríndias.

Assim, Treece observa que, apesar do destaque concedido ao amor filial - um valor europeu - no personagem de I-Juca-Pirama durante a desintegração tribal, a ação que conclui o poema é contrária. Ou seja, o clímax de "I-Juca-Pirama" é o reestabelecimento da lógica guerreira, que ocorre necessariamente com a consumação do rito canibal (TREECE, p. 187).

Ao oferecer uma leitura dessa prática que se aproxima do conhecimento antropológico moderno sobre o assunto, Gonçalves Dias rompeu com toda uma tradição de literatura indianista no Brasil, que, por três séculos, representou e caricaturou o canibalismo como prova da barbárie primitiva do índio, como vimos no último capítulo. De fato, ele é único no indianismo do século dezenove por essa interpretação, e, depois dele, teve-se que esperar pelo movimento modernista para que a significação ritual do canibalismo fosse novamente reafirmada. Tal revisão radical de uma das pedras fundamentais do discurso colonial fala alto pela notável contribuição deste poeta como uma das mais poderosas vozes dissidentes no seio da tradição romântica indianista (TREECE, p. 191).

Certamente se pode problematizar a noção de "literatura brasileira" antes dos períodos setecentista e oitocentista. No entanto, o que eu gostaria de frisar na interpretação de Treece é a originalidade que o crítico percebe na obra indianista de Gonçalves Dias não apenas em função do critério formal dos poemas, mas também em função do critério de tratamento da temática indígena.

Por um lado, segundo Candido e Bosi, Gonçalves Dias é o melhor poeta de seu contexto porque soube criar uma nova convenção poética, além de ter apresentado o Indianismo autenticamente. Por outro, segundo 
Lúcia Sá e David Treece, Gonçalves Dias foi um indianista destacado em meio ao bloco romântico porque soube interpretar os escritos coloniais sobre as culturas ameríndias, deles se apropriando criticamente.

Assim, a aproximação de Gonçalves Dias a Montaigne que Matos opera é compreensível, já que o filósofo procurou interpretar as sociedades ameríndias por meio da desconstrução de seu próprio ponto de vista. Nota-se que Montaigne procura descrever os valores canibais: "[...] prega aos ocupantes sem cessar as mesmas coisas: valentia diante do inimigo e amizade a suas mulheres. E nunca esquecem [...] de lhes lembrar que são elas que fabricam a bebida e a conservam morna" (MONTAIGNE, 1975, p. 102).

Além disso, Montaigne, ao descrever o ritual canibal, desenvolve um deslocamento. Enquanto a maior parte dos cronistas relata o canibalismo pelo viés cristão e com ênfase na ingestão da carne, Montaigne aborda-o pelo canto. Ele desloca o canibalismo do status de prática bárbara para o status discursivo:

Eis o que diz: "Que se aproximem todos com coragem e se juntem para comê-lo; em o fazendo comerão seus pais e seus avôs que já serviram de alimento a ele próprio e deles seu corpo se constituiu. Estes músculos, esta carne, estas veias, diz-lhes, são vossas, pobres loucos. Não reconheceis a substância dos vossos antepassados que no entanto ainda se encontram em mim? Saboreai-os atentamente, sentireis o gosto de vossa própria carne”. Haverá algo bárbaro nesta composição? (MONTAIGNE, p. 105).

Podemos interpretar que a percepção da crítica de uma convergência de Gonçalves Dias em relação à fonte do ensaio de Montaigne - no que diz respeito à valorização do discurso no rito canibal - pode traduzir-se também como convergência com ideias que seriam mais tarde propostas pela antropologia, no campo científico, e com ideias que seriam reformuladas pelo modernismo, no campo artístico. Conforme citado acima, David Treece defende como o movimento antropofágico deu continuidade ao gesto gonçalvino em relação ao canibalismo. Lúcia Sá também estabelece esse tipo de repercussão da obra de Gonçalves Dias.

À luz desse tipo de reflexão, portanto, torna-se relevante examinar a intertextualidade criteriosa que Gonçalves Dias estabeleceu com os cronistas. A partir das notas do autor, por exemplo, podem-se traçar alguns dados da pesquisa que ele realizou tanto para o indianismo, quanto para o medievalismo. No caso das Poesias americanas, a citação direta se refere aos textos coloniais, como os de Jean de Léry, Hans Staden, Padre Simão de Vasconcelos, João de Laet, Damião de Góis, Nicolas 
Barré e António Vieira. Dias citatambém os historiadores Ferdinand Denis e Robert Southey.

Ao considerar o cotejo dos cronistas e dos viajantes, podemos abordar poemas de Gonçalves Dias por meio de diferentes chaves-de-leitura. Nesse sentido, o significado da guerra em sua poesia pode distanciar-se do medievalismo e ser lido como um sistema específico das sociedades ameríndias.

Hans Staden (1557), que é muitas vezes citado por Gonçalves Dias, descreve, por exemplo, a "maior honra" tupinambá, notando a valentia na guerra constante:

Considera um homem sua maior honra capturar e matar muitos inimigos, o que entre eles é habitual. Traz tantos nomes quantos inimigos matou, e os mais nobres entre eles são aqueles que têm muitos nomes (STADEN, 1988, p. 172).

Jean de Léry descreve o rito canibal e suas preparações, com ênfase na valentia e no diálogo entre o executor e o prisioneiro que está prestes a ser morto, moqueado e ingerido:

Com efeito, estando eu numa aldeia chamada Sariguá, vi um prisioneiro lançar uma pedra com tanta violência na perna de uma mulher que supus havê-la quebrado. Esgotadas as provisões de pedras e cacos e de tudo que o prisioneiro pôde apanhar junto de si, o guerreiro designado para dar o golpe, e que permanecera longe da festa, sai de sua casa, ricamente enfeitado com lindas plumas, barrete e outros adornos; e armado de um enorme tacape aproxima-se do prisioneiro e lhe dirige as seguintes palavras: "Não és tu da nação dos maracajás, que é nossa inimiga? Não tens morto e devorado aos nossos pais e amigos?"

O prisioneiro, mais altivo do que nunca, responde no seu idioma (margaiás e tupiniquins se entendem reciprocamente) pá, che tan tan ajucá atupavé - "Sim, sou muito valente e realmente matei e comi muitos".

Em seguida, para excitar ainda mais a indignação do inimigo, leva as mãos à cabeça e exclama: "Eu não estou a fingir, fui, com efeito, valente e assaltei e venci os vossos pais e os comi". E assim continua até que seu adversário, prestes a matá-lo, exclama: "Agora estás em nosso poder e serás morto por mim e moqueado e devorado por todos". Mas tão resoluta quanto Atílio Régulo ao morrer pela República Romana, a vítima ainda responde: "Meus parentes me vingarão" (LÉRY, 1980, p. 196). 
Gândavo (1576) descreve a centralidade da guerra entre os indígenas, porém, segundo termos de racionalização da colonização portuguesa:

[...] ninguém pode pelo sertão dentro caminhar seguro, nem passar por terra onde não acha povoações de indios armados contra todas as nações humanas, e assi como são muitos permitiu Deos que fossem contrários huns dos outros, e que houvesse entrelles grandes ódios e discórdias, porque se assi não fosse os portuguezes não poderião viver na terra nem seria possível conquistar tamanho poder de gente (GÂNDAVO, 1980, p. 52).

Estes indios são mui belicosos e têm sempre grandes guerras uns contra os outros; nunca se acha nelles paz nem hepossivel haver entrelles amizade; porque humas nações pelejão contra outras e matão-se muitos deles, e assi vai crecendo o ódio cada vez mais e ficão imigos verdadeiros perpetuamente (GÂNDAVO, p. 54).

Gândavo descreve como os indígenas decidem guerrear ou não, segundo "agouros" ou "prognósticos", e como sempre são valentes, caso não recebam premonições desfavoráveis (GÂNDAVO, p. 132). Relata também o diálogo desenvolvido antes do sacrifício canibal (GÂNDAVO, p. 137).

Já d'Abbeville (1614) chama atenção para a peculiaridade da guerra indígena, quando comparada à guerra conhecida pelos europeus:

É preciso primeiramente que se saiba que não fazem a guerra para conservar ou estender os limites de seu país, nem para enriquecer-se com os despojos de seus inimigos, mas unicamente pela honra e pela vingança. Sempre que julgam ter sido ofendidos pelas nações vizinhas ou não, sempre que se recordam de seus antepassados ou amigos aprisionados e comidos pelos seus inimigos, excitam-se mutuamente à guerra, a fim, dizem, de tirar desforra, de vingar a morte de seus semelhantes (D'ABBEVILLE, 1975, p. 229).

[2] Cf., por exemplo, Cap. XLIX, especialmente p. 234. D'ABBEVILLE, Claude. História da missão dos padres capuchinhos na llha do Maranhão e terras circunvizinhas. São Paulo: EDUSP; Belo Horizonte: Itatiaia, 1975
Em algumas passagens do texto, d'Abbeville justifica a catequese como forma de salvar os indígenas das práticas "bárbaras" e "cruéis"2 (D'ABBEVILLE, p. 229). Com frequência, porém, seu relato constitui observação detalhada das sociedades ameríndias. Ele descreve, por exemplo, o ritual para exortar os meninos a se tornarem guerreiros valentes (D'ABBEVILLE, p. 214). Descreve também o diálogo que precede o sacrifício canibal:

Apresenta-se o ancião diante do prisioneiro e lhe faz o seguinte discurso: "Não sabes que tu e os teus mataram muitos parentes nossos 
e muitos amigos? Vamos tirar a nossa desforra e vingar essas mortes. Nós te mataremos, assaremos e comeremos"; "Pouco me importa, responde a vítima, pois não morrerei como um vilão ou um covarde. Sempre fui valente na guerra e nunca temi a morte. Tu me matarás, porém eu já matei muitos companheiros teus. Se me comerdes, fareis apenas o que eu já fiz eu mesmo. Quantas vezes me enchi com a carne de tua nação! Ademais, tenho irmãos e primos que me vingarão (D'ABBEVILLE, p. 232).

Também Hans Staden descrevera a prática do rito canibal quanto ao modo de preparar o prisioneiro, realizar a cauinagem, dançar, matar e comer (STADEN, pp. 179-188). Ele cita igualmente o discurso entre o homem que executa e a vítima:

A seguir retoma o tacape aquele que vai matar o prisioneiro e diz: "Sim, aqui estou eu, quero matar-te, pois tua gente matou e comeu muitos dos meus amigos". Responde-lhe o prisioneiro: "Quando estiver morto, terei ainda muitos amigos que saberão vingar-me". Depois golpeia o prisioneiro na nuca, [...] (STADEN, p. 182).

Portanto, ao pensar na guerra constante como um dos eixos dessas sociedades ameríndias, podemos mudar a perspectiva sobre o indianismo gonçalvino. Em "O canto do guerreiro", por exemplo, o índio composto por Gonçalves Dias vai à guerra por valentia. Os preparativos para a guerra são descritos de maneira conforme à descrição dos cronistas. As habilidades do guerreiro, também.

A exortação contínua da guerra, o canto dos piagas, a cauinagem, a permanência do ciclo vingativo e o rito canibal são elementos estranhos ao medievalismo e à lógica ocidental. No entanto, estão presentes na poesia indianista gonçalvina antes como aspectos estruturantes do que como elementos de cor local.

É possível desenvolver essa observação na leitura de "I-Juca-Pirama”, por exemplo. Nesse poema, Gonçalves Dias criou a circunstância impensável na qual um guerreiro indígena nega participar do rito canibal. Independentemente da improbabilidade da cena (ou talvez por esse fator), creio que haja uma relação entre o contexto histórico de Gonçalves Dias, aspectos das culturas ameríndias em questão e a forma do poema.

Ou seja, para além da versificação com emprego do anapesto ${ }^{3}$ e da citação de elementos da tradição dos Timbiras e dos Tupi, em "I-Juca-Pirama", Gonçalves Dias toca num ponto nevrálgico do canibalismo. Trata-se do diálogo que precede o sacrifício. Conforme a interpre-

[3] O emprego do anapesto na poesia gonçalvina é referido pela maior parte dos críticos. Para citar um exemplo, Bosi comenta a "ductibilidade dos ritmos" de "I-Juca-Pirama" e afirma: "Martelado nas tiradas de coragem, até o emprego do anapesto nas apóstrofes célebres da maldição: Sou bravo, sou forte,/[...]" (Bosı, p. 118). 
[4] Eduardo Viveiros de Castro, ao analisar as diferentes dimensões temporais implicadas no diálogo canibal, interpreta o problema do futuro da seguinte forma: "Qual o conteúdo dessa memória instituída por e para a vingança? Nada, senão a própria vingança, isto é, uma pura forma: a forma pura do tempo, a desdobar-se entre os inimigos. Com a permissão de Florestan Fernandes (1952), não penso que a vingança guerreira fosse um instrumentumreligionis que restaurava a integridade do corpo social ameaçado pela morte de um membro, fazendo a sociedade voltar a coincidir consigo mesma, religando-a aos ancestrais mediante o sacrifício de uma vítima. Não creio, tampouco, que o canibalismo fosse um processo de "recuperação da substância" dos membros mortos, por intermédio do corpo devorado do inimigo. Pois não se tratava de haver vingança porque as pessoas morrem e precisam ser resgatadas do fluxo destruidor do devir; tratava-se de morrer (em mãos inimigas de preferência) para haver vingança, e assim haver futuro. Os mortos do grupo eram o nexo de ligação com os inimigos, e não o inverso. A vingança não era um retorno, mas um impulso adiante; a memória das mortes passadas, próprias e alheias, servia à produção do dervir. A guerra não era uma serva da religião, mas o contrário" (CASTRO, 2013, p. 240). tação de Eduardo Viveiros de Castro (2002), o diálogo do rito canibal não reconstrói a memória social apenas. Antes de tudo, ele instaura coletivamente a possibilidade de dar continuidade ao futuro ${ }^{4}$.

Acima, nos trechos em que os cronistas descrevem o diálogo entre o executor e a vítima, há a resposta do segundo que diz que os seus irão vingá-lo. No caso de I-Juca-Pirama, os seus foram exterminados pelo genocídio colonial, com exceção do pai, que é um velho doente e faz valer a tradição guerreira dos Tupi.

No caso, os laços sanguíneos não são valores absolutos. Eles podem ser flexionados perante o valor prioritário da valentia e da honra, como se expressa na fala do pai:
Tu choraste em presença da morte?
Na presença de estranhos choraste?
Não descende o cobarde do forte;
Pois choraste, meu filho não és!
Possas tu, descendente maldito
De uma tribo de nobres guerreiros,
Implorando cruéis forasteiros,
Seres presa de vis Aimorés
(DIAS, 1998, p. 389).

Assim, no poema, quando a lógica guerreira é reestabelecida, o sacrifício de I-Juca-Pirama passa a ter um significado paradoxal. Ao morrer, ele reafirma a tradição. No entanto, ele não possui resposta plausível no diálogo canibal, já que este não tem condições de ocorrer devido ao extermínio da tribo. Com a morte do último jovem guerreiro tupi, encerra-se a possibilidade de alimentar a vingança e de dar continuidade à tradição.

Portanto, Gonçalves Dias propõe a denúncia do genocídio indígena causado pela invasão europeia. A obra gonçalvina articula esse tipo de consciência crítica por meio de poemas que estão intrinsecamente ligados a instituições fundamentais das sociedades ameríndias, como a guerra e o rito canibal, cujos valores são estranhos à lógica medievalista. Igualmente, em Gonçalves Dias, há a referência formal a gêneros indígenas, como o canto de exortação, o canto xamânico e a canção natalícia.

Nesse sentido, é válido desenvolver leituras que considerem o crivo crítico com o qual o poeta leu a tradição de textos coloniais. Isto porque Gonçalves Dias é extremamente cuidadoso na abordagem da matéria indígena. Ao atentar para a forma como sua obra poética se refere às fontes de escritos coloniais, podemos distanciar-nos do lugar-comum da recepção crítica brasileira, segundo o qual, o índio gonçalvino é uma 
mera reprodução do cavaleiro medieval. Dessa forma, distanciamo-nos da orientação de julgar uma obra poética particular por meio de características gerais da escola.

No entanto, ao mesmo tempo, a poética de Dias insere-se num movimento romântico que caracteriza a figura do índio como heroi nacional e que compartilha pressupostos ideológicos com a política imperial, especialmente no que diz respeito a um projeto de nação. Assim, é igualmente produtivo retomar a posição tensa que Gonçalves Dias ocupou no quadro ideológico do Império. Como já citado, essas são questões que vêm sendo propostas pela crítica recente do poeta, como ocorre nas obras de Lúcia Sá e de David Treece. I 


\section{REFERÊNCIAS}

d'ABBEVILLE, Claude d'. História da missão dos padres capuchinhos na Ilha do Maranhão e terras circunvizinhas. São Paulo: EDUSP; Belo Horizonte: Itatiaia, 1975.

BOSI, Alfredo. História concisa da literatura brasileira. São Paulo: Editora Cultrix, 1975.

CANDIDO, Antonio. Formação da literatura brasileira: momentos decisivos (1750-1880). Rio de Janeiro: Ouro sobre Azul, 2007.

CASTRO, Eduardo Viveiros de Castro. "O mármore e a murta: sobre a inconstância da alma selvagem”. In: A inconstância da alma selvagem. São Paulo: Cosac e Naify, 2013, pp. 182-264.

DIAS, Gonçalves. Poesia. In: Gonçalves Dias: poesia e prosa completas. Rio de Janeiro: Nova Aguilar, 1998, pp. 93-723.

GÂNDAVO, Pero de Magalhães. História da províncias de Santa Cruz. Tratado da Terra do Brasil. São Paulo: EDUSP; Belo Horizonte: Itatiaia, 1980.

LÉRY, Jean de. Viagem à terra do Brasil. São Paulo: EDUSP; Belo Horizonte: Itatiaia, 1980.

MATOS, Cláudia Neiva de. Gentis guerreiros: o Indianismo de Gonçalves Dias. São Paulo: Atual, 1988.

MONTAIGNE, Michel de. "Dos canibais". In: Ensaios. São Paulo: Abril Cultural, 1984, pp. 100-106

ROUSSEAU, Jean-Jacques. Os devaneios do caminhante solitário. Brasília: Editora da Universidade de Brasília, 1986.

SÁ, Lúcia. Literatura da floresta: textos amazônicos e cultura latino-americana. Rio de Janeiro: EdUERJ, 2012.

STADEN, Hans. Duas viagens ao Brasil. São Paulo: EDUSP; Belo Horizonte: Itatiaia, 1974.

TREECE, David. Exilados, aliados, rebeldes: o movimento indianista, a política indígena, e o estado-nação imperial. São Paulo: Nankin, Edusp, 2008. 
